\title{
The MACv2 Aerosol Climatology
}

\author{
S.Kinne, MPI-Meteorology, Hamburg, Germany (e-mail: stefan.kinne@mpimet.mpg.de)
}

\begin{abstract}
The MAC aerosol climatology defines monthly global maps for aerosol properties. The definition of midvisible optical and microphysical properties is strongly linked to multi-year statistics of observations by sun-photometers of the AERONET and MAN ground networks. As available statistics is spatially sparse, context from bottom-up global modeling is added. Now in its second version, oceanic MAN reference data are included, a different lower anthropogenic fraction is assumed and the merging of the datastatistics is improved. Hereby, now only absolute properties are merged and trusted photometer data are given stronger weights via regional corrections in place of local domain limited corrections. Global average mid-visible $(550 \mathrm{mn})$ aerosol properties are 0.12 for the aerosol optical depth (AOD), 0.94 for the single scattering albedo (SSA) and 0.7 for the asymmetry-factor (ASY). Averages for sub-micrometer (fine-mode) and super-micrometer (coarse-mode) aerosol sizes are 0.63 (AODf) / 0.58 (AODc), 0.92 (SSAf) /0.965 (SSAC) and 0.64 (ASYf) / 0.77 (ASYc), respectively. A new element is the separation of aerosol absorption (AAOD) by sky-/sun-photometers into fine-mode and coarse-mode contributions. These properties as well as the fine-mode effective radii were merged with background data from global modeling yielding global averages of 0.050 (AAODf), 0.021 (AAODc) and 0.18um (re,f). Local monthly mode detail now allows (in a 'top-down' approach) to extract global distributions for aerosol component amount and size. As the considered components for soot (BC), organics (OC), non-absorbing fine-mode $(S U)$, sea-salt (SS) and mineral dust (DU) have pre-defined spectrally resolved properties, optical properties at other than mid-visible wavelengths are automatically defined - as required in broadband radiative transfer applications. With component information (e.g. amount, composition and size) also MAC estimates for CCN and IN concentrations are possible and also a simple MAC based aerosol retrieval model for satellite sensor data is suggested.
\end{abstract}

\section{Introduction}

Tropospheric aerosols originate from many sources of natural (e.g. windblown dust, sea-spray, wildfires) or anthropogenic origin (e.g. fossil fuel burning, agricultural burning). Since also the aerosol lifetime is only on the order of a few days (mainly due to the removal by precipitation), tropospheric aerosols are highly variable in concentration and composition. However, only aerosol sizes larger than a tenth of a micrometer in size (>0.05um in radius) directly influence the radiative energy distribution in 
the atmosphere. Sub-micrometer (fine-mode) sizes only affect the solar radiative transfer, while supermicrometer (coarse-mode) sizes modulate both solar and terrestrial radiative energy distributions.

Although the influence of aerosols is small compared to that of clouds, there is from a climate change perspective still a strong interest in the impact of aerosol (as small as it may be) because part of today's atmospheric aerosol is anthropogenic in nature. However, quantifying global aerosol radiative effects via model simulations is rather complex, as emissions of different aerosol species and pre-cursor gases need to be chemically and/or cloud processed, mixed, transported and removed. Moreover, the resulting aerosol mass must then be converted into aerosol optical properties (with assumptions to size and water uptake) so that associated aerosol radiative effects can be determined with radiative transfer methods. As a result, these 'bottom-up' simulations are rather time-consuming and there is a need for simpler methods.

The direct provision of likely aerosol optical properties, if possible based on optical measurements, circumvents the need for complex aerosol processing. Then only a radiative transfer method has to be applied to determine radiative effects - although climate change estimates still suffer from uncertainties to the pre-industrial reference state. As optical measurements inform on aerosol amount and aerosol absorption as function of size and even on size-distributions, detailed information on the aerosol composition and mixture and even mass can be derived. Thus, the approach starting from aerosol optical properties (with respect to aerosol components) is referred to as 'top-down' approach.

A 'top-down' approach is the topic of this contribution. Hereby, all (for radiative transfer simulations relevant) aerosol optical properties are provided via monthly climatologies with global coverage. Building on the concept of MACv1 (Kinne et al., 2013), the updated MACv2 version is introduced.

\section{2. mid-visible column properties}

2.1 What is MAC? The Max Planck institute Aerosol climatology (MAC) is defined by monthly global ( $1 \times 1$ deg) fields for aerosol optical and microphysical properties. Central to these fields are atmospheric column aerosol optical properties in the mid-visible spectral region. These column properties are based on trusted ground-based observations sampled over the last two decades. As observations are sparsely distributed, context from global 'bottom-up' modeling is added to yield spatially and temporally complete fields. In a so-called 'merging process' - monthly maps from global modeling are adjusted as suggested by monthly statistics of ground based solar photometry. Contributing solar photometry data are sun- and sky- samples by CIMEL instruments of the AERONET network (Holben et al. 2001) and sunsamples by handheld MICROTOPS instruments of the Marine Aerosol Network, MAN (Smirnov et al., 2009). The maps from modeling are defined by local monthly medium values of 14 different AeroCom (phase1) models (Kinne et al., 2006). For a flavor of the applied aerosol data in the development of the MAC climatology, annual averages of input maps for four important aerosol properties are compared in Figure 1 between by sun-/sky photometry (AERONET / MAN) and modeling (AeroCom). 

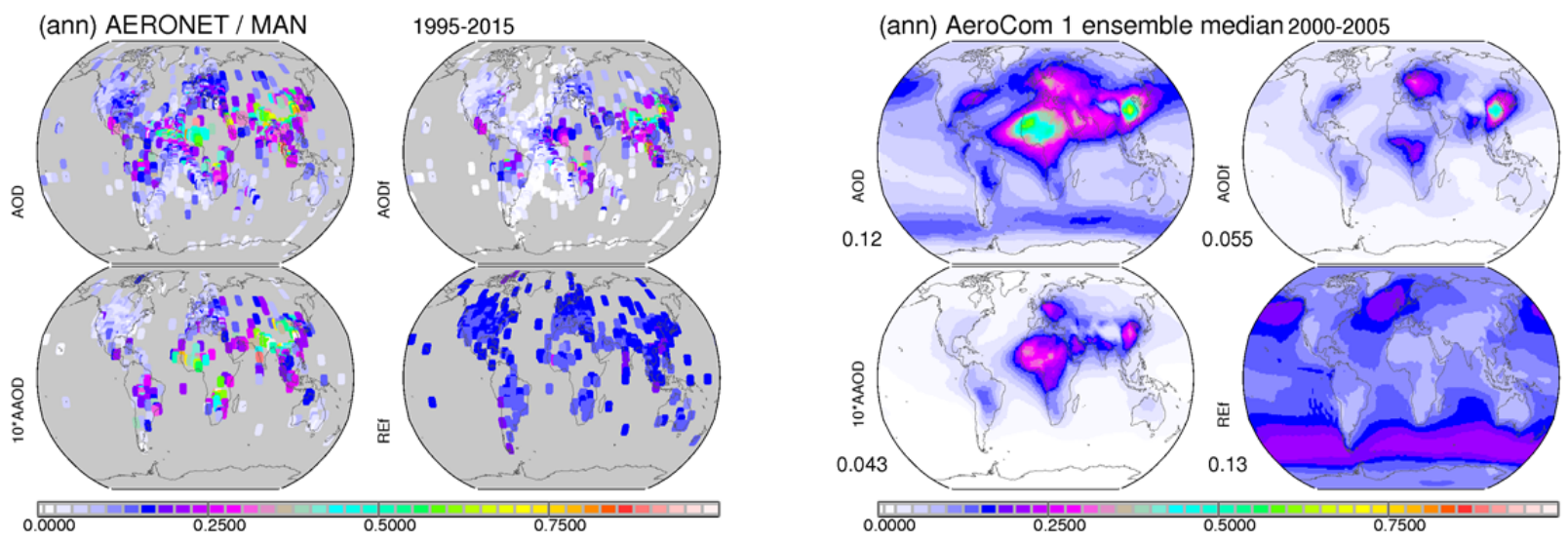

Figure 1. Input data of MACV2. Shown are the multi-annual averages of aerosol optical properties at $550 \mathrm{~nm}$ based on sun-photometer measurements by AERONET and MAN (left block, local data are enlarged for better viewing) and by the AeroCom 'bottom-up' modeling ensemble (right block). The four sub-panels in each block display the aerosol optical depth AOD (upper left), the absorption aerosol optical depth AAOD (lower left, multiplied by a factor 10), the fine-model aerosol optical depth AODf (upper right) and the fine-mode effective radius REf (lower right). The sun-photometer data coverage over oceans is higher for $A O D$ and AODf due to the additional MAN data.

2.2. What has changed since MACv1? Compared to the initial MACv1 version (Kinne at al., 2013) major upgrades are incorporated. In MACV2 (1) more recent AERONET data are included so that the central reference year shifted from year 2000 to year 2005, (2) MAN data over oceans are now considered, (3) a new regional data merging procedure is applied, (4) only absolute properties are merged (e.g. AAOD instead of SSA), (5) pre-defined aerosol types are utilized to assign local component mixtures and (6) a new (smaller) anthropogenic fraction is applied.

2.3. What trusted quality data are applied? Solar photometry measurements from the ground offer at cloud-free conditions reliable atmospheric column data for all aerosol properties of amount, size (distribution), and absorption. Together these (three) properties even inform about compositional mixtures. Particular accurate are direct solar attenuation data for aerosol column amount via the aerosol optical depth (AOD). Sun-photometers sample AOD data at different solar wavelengths (e.g. AERONET's CIMEL instrument samples at 380, 440, 500, 670, 870 and $1020 \mathrm{~nm}$ ) so that estimates on fine-mode versus coarse-mode AOD contributions are revealed (O'Neill et al., 2003). In addition, solar spectral sky-radiance samples in near forward and side scattering directions offer (via inverse radiative transfer methods) aerosol size distribution detail and absorption estimates (e.g. the Dubovik et al, 2000 algorithm applied to AERONET'S CIMEL data expresses absorption via refractive index imaginary parts at $440,670,870$ and $1020 \mathrm{~nm})$. 
2.3.1 aerosol column amount: Direct solar attenuation (at cloud-free conditions) data define the AOD, here interpolated to $550 \mathrm{~nm}$ (the reference wavelength in modeling and remote sensing ). The AOD spectral dependence allows to separate AOD attributions to smaller (fine-mode, $r<0.5 u m$ : AODf) and larger (coarse-mode, $r>0.5 \mathrm{um}, \mathrm{AODc}$ ) aerosol sizes. The applied samples originate from more than 700 continental or island sites worldwide of the AERONET network (https://aeronet.gsfc.nasa.gov/) collected between 1995 and 2015 and from more than 100 ship-cruises over oceans between 2006 and 2015 (https://aeronet.gsfc.nasa.gov/new web/maritime aerosol network.html) offered by the Marine Aerosol Network (MAN).

2.3.2 aerosol absorption: The retrieved imaginary parts of the refractive index define the aerosol absorption. The aerosol absorption is quantified by the Absorption Aerosol Optical Depth (AAOD). The AAOD (= AOD* [1-SSA]) is the product of AOD and the absorption potential 1-SSA (where SSA as Single Scattering Albedo defines the scattering potential). For atmospheric aerosol the scattering potential (SSA) in the mid-visible is on average a magnitude larger than the absorption potential (1-SSA). Thus, at lower aerosol loads the reduced sky scattering due to absorption is difficult to detect and only absorption data at larger aerosol loads (AOD at $550 \mathrm{~nm}>0.2$ ) are reliable. For lower aerosol loads, the absorption potential (1-SSA) of statistically larger (or if necessary of the largest) aerosol loads at each site are prescribed in order maintain reliable estimates (rather than introducing a bias with the removal of low AOD cases). The spectral dependence of the AAOD data in conjunction with the AOD attribution to the fine-mode (via the Fine-Mode AOD Fraction: FMF = AODf / AOD) offers sufficient information to separate aerosol absorption (AAOD) into fine-mode (AAODf) and coarse-mode (AAODc) contributions.

$$
\begin{aligned}
& \text { AAODf, } 550=A A O D, 550 * F^{*} F^{*}(A * B / C) \text { with } \mathbf{F M F}=\text { AODf, } 550 / A O D, 550 \\
& \mathrm{AAODc}, 550=\mathrm{AAOD}, 550-\mathrm{AAODf}, 550 \quad \mathrm{~A}=0.2+0.25 *(1-\mathrm{FMF})^{* * 2} \text {, } \\
& B=\ln (A A O D, 440 / A A O D, 670) / \ln (.67 / .44) \\
& \text { C }=\min (\ln (A A O D, 670 / A A O D, 1020) / \ln (1.02 / .67), B)
\end{aligned}
$$

2.3.3 aerosol size: The relevance of aerosol size is already addressed, as amount and absorption of aerosol is (as explained above) already split into contributions by sub-micrometer (fine-mode) aerosol and super-micrometer (coarse-mode) sizes. In addition, detailed size distribution concentration data for sizes smaller than $0.5 \mathrm{um}$ in radius determine the effective radius (re=sum $\{n * r * 3\} / \operatorname{sum}\{n * r * * 2\}$ ) of the fine-mode (REf). REf is an important parameter to estimate the aerosol number concentrations of optically detectable sizes ( $r>0.05 \mathrm{um}$ ) and essential for reliable CCN estimates with MACv2 data.

2.4. How are data merged? The merging combines the accuracy of local photometer statistics with gapfilling spatial context by global modeling. First, solar photometer data (sampled between 1995 and 2015) are combined and gridded to the monthly and $1 \times 1 \mathrm{deg}$ lat/lon spatially resolution of global modeling. Then, global sub-regions with sufficient photometer sites are picked as illustrated in Figure 2. In those regions for each month interquartile averages of only matching grid-points are compared. Their ratio (photometer to modeling data) defines multipliers that are applied to modeling background maps in that region (and month). Finally, spatial inconsistencies of multipliers at regional boundaries are smoothed. Annual adjustment multipliers for the four properties of Figure 1 are presented in Figure 2. 

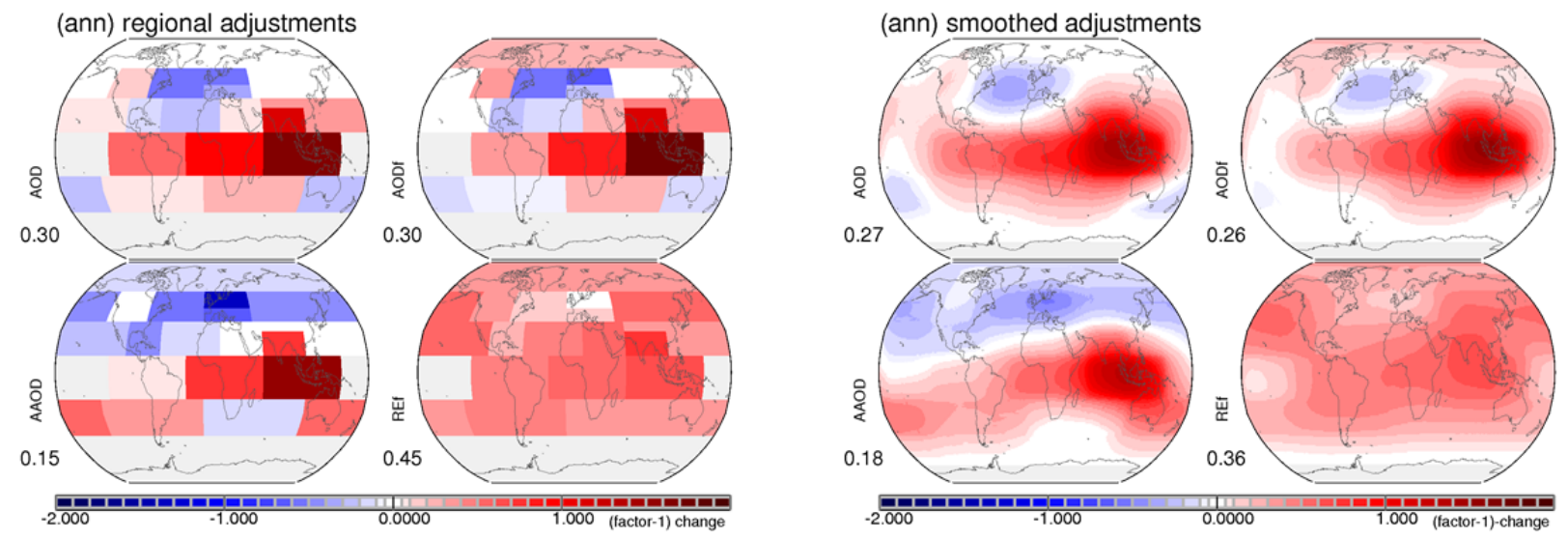

Figure 2. AERONET/MAN observation suggested (factor-1) changes to background data from modeling for the four properties of Figure 1 - by region. Red colors indicate the need to increase model properties (with 1 referring to a doubling), blue colors require a reduction (with -1 referring to half the value) and grey colors indicate no changes due to a lack in reference data. Presented are for the four properties of Figure 1 annual average adjustments for the selected 21 regions (left block) and applied adjustments after smoothing (right block). Values below labels are adjustment averages.

The smoothed adjustments of Figure 2 applied to the AeroCom 1 ensemble data in Figure 1 (AOD, AAOD, AODf and REf) yield the maps MACv2 annual maps in Figure3.
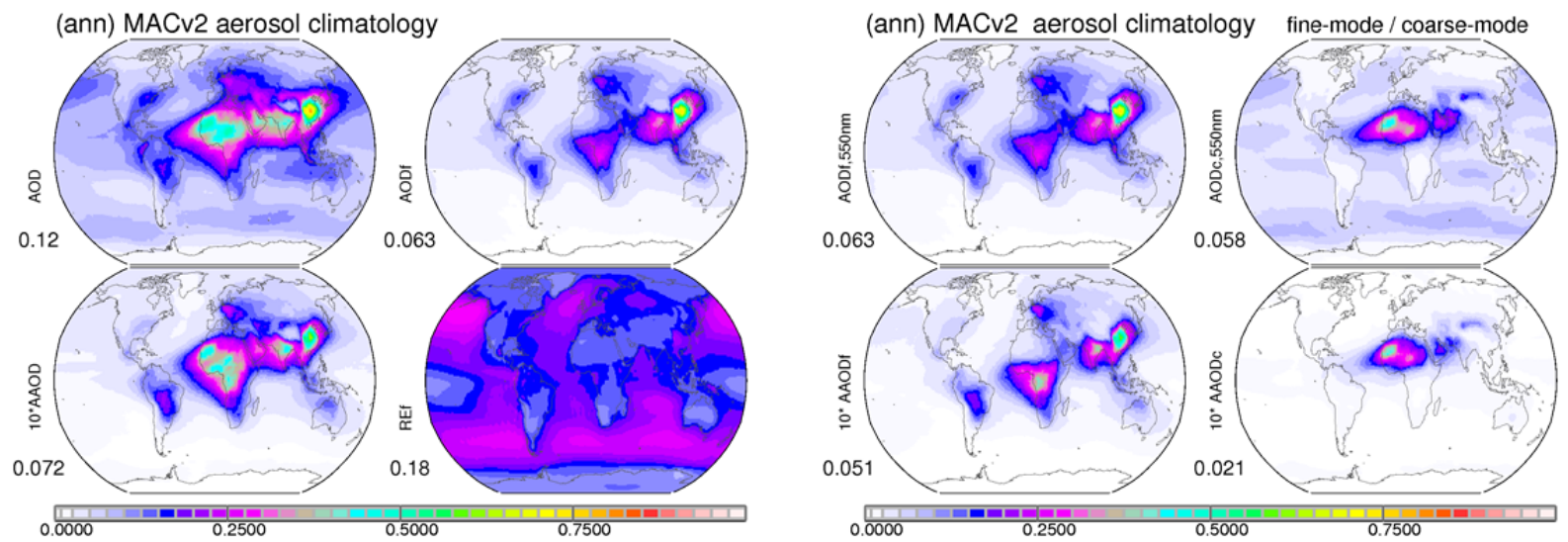

Figure 3. annual average maps of the MACv2 aerosol climatology. Global distributions (as result of the data-merging) are presented (left block) for the mid-visible AOD (column amount), for the mid-visible $A A O D$ (column absorption - here multiplied by 10 to fit the common scale) and for the fine-mode properties for the mid-visible AOD (AODf) and effective radius (REf). Also presented are by size-mode annual maps for $A O D$ and $10 * A A O D$ maps for the fine-mode (right block, left column) and coarse-mode (right block, right column). Values below labels present global averages. 
Figure 3 also presents annual maps for AOD and AAOD properties separately merged for fine-mode aerosol (AODf and AAODf) and for coarse mode aerosol (AODc and AAODC). While there is similarity in the maps for AOD and the order of magnitude lower AAOD for each size-mode, the spatial distributions between fine-mode (maxima over urban and biomass burning region) and coarse mode (maxima of dust regions) are quite different. On a global average basis both size-modes contribute about evenly to the total AOD (ca $50 \%$ vs $50 \%$ ), while the fine-mode contributes stronger to the AAOD (ca $70 \%$ vs $30 \%$ ). Hereby, coarse mode absorption increases with an increase in the mineral dust size. This AAODc sizedependence will be later used to extract size information on dust, whereas merged REf data constrain not only fine-mode aerosol sizes but also (fine-mode controlled) aerosol concentrations.

\section{3. components}

3.1 why components? Tropospheric aerosol is always a mixture of many different sources. Breaking these spatially and in time varying mixtures down into radiatively well-defined components has several advantages. Most importantly, it allows a deterministic definition of aerosol radiative properties at other spectral regions (e.g. to satisfy satellite sensor or broadband radiative transfer requirements) and it allows to address radiative impacts of individual components (similar to approaches in 'bottom-up' modeling). Fortunately, MACv2 optical properties (AODf, AAODf, AODc and AAODc) and MACv2 finemode size information (REf) together provide sufficient detail so that not only an AOD separation into components is possible but also detail on component size and aerosol concentrations can be extracted.

3.2 what aerosol components are considered? Adopting the aerosol component choices in global modeling five different components are considered with distinct differences in size and absorption. Components of sulfate (SU), organic carbon (OC), OC coated BC (CA), mineral dust (DU) and sea-salt (SS) are selected and their size and composition properties are postulated - in terms of log-normal sizedistributions and spectrally varying refractive indices, as summarized in Table 1 and in Figures 4 and 5 .
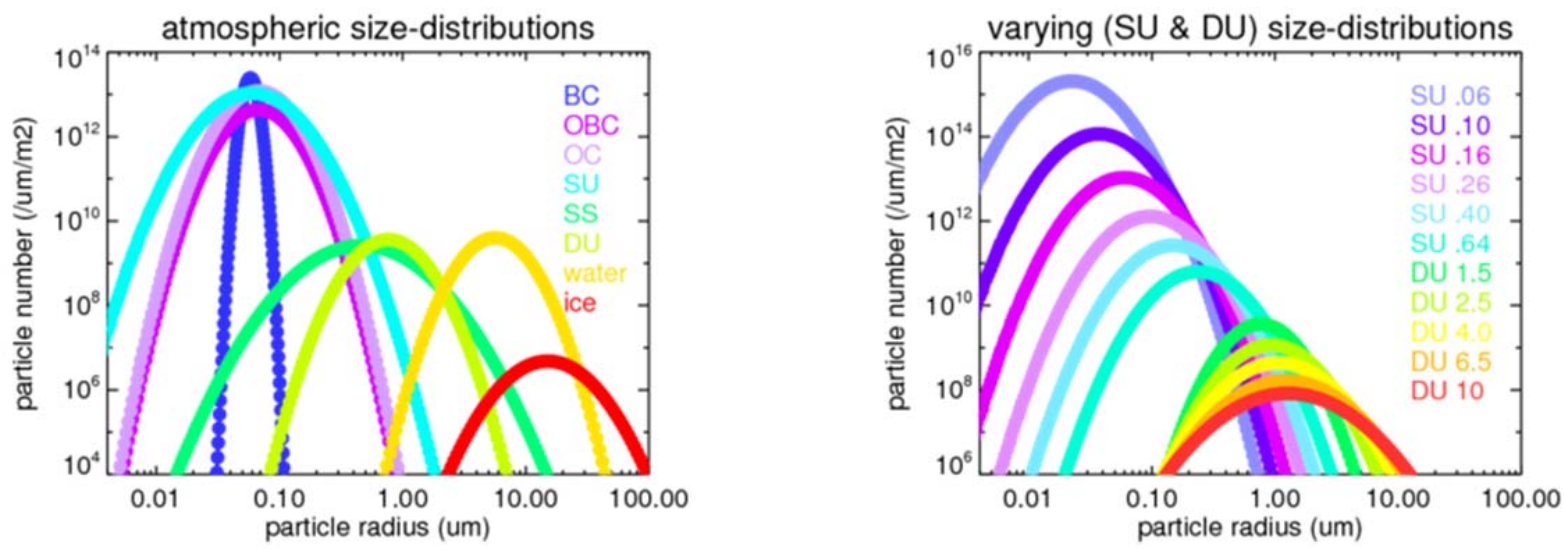

Figure 4 Size-distributions of standard aerosol components (left block, with those for a water and ice cloud as reference) und for different sizes of sulfate and dust (right block, with effective radius values) 
Table 1 pre-defined aerosol types with assumed log-normal size-distribution parameters ( $\mathrm{rm}$, sd) and assumed mid-visible refractive indices. Also given are resulting MACv2 associated global mid-visible component aerosol optical depths and the associated atmospheric component particle number. For comparison typical values of a cumulus water cloud and a cirrostratus ice cloud are provided as well.

\begin{tabular}{|c|c|c|c|c|c|c|c|c|c|c|}
\hline aerosol type & label & $r_{e}$ & $r_{m}$ & $S_{d}$ & $\mathbf{R F}_{\mathrm{R}}$ & $\mathbf{R F}_{\mathbf{I}}$ & SSA & opt.D & MEE & $\mathbf{N}$ \\
\hline & & [um] & [um] & & \multicolumn{4}{|c|}{ at 550nm wavelength } & $m 2 / g$ & {$[\# / m 2]$} \\
\hline soot & $B C$ & .06 & .03 & 1.7 & 1.70 & .700 & .155 & 0.004 & 8.9 & $3.4 e+12$ \\
\hline organic & $\mathrm{OC}$ & .12 & .06 & 1.7 & 1.53 & .005 & .970 & 0.022 & 3.0 & $9.0 \mathrm{e}+12$ \\
\hline soot + o.shell & $\mathrm{CA}$ & .12 & .06 & 1.7 & & & .615 & 0.012 & & $3.2 \mathrm{e}+12$ \\
\hline sulfate * & SU & .16 & .08 & 1.7 & 1.43 & .000 & .999 & 0.037 & 3.2 & $1.9 e+12$ \\
\hline seasalt & SS & 2.5 & .75 & 2.0 & 1.50 & .000 & .999 & 0.028 & 0.31 & $2.6 e+10$ \\
\hline dust * & DU & 1.5 & .93 & 1.55 & 1.53 & .001 & .962 & 0.031 & 0.27 & $3.4 \mathrm{e}+10$ \\
\hline cloud water & water & 10 & 6.7 & 1.5 & 1.33 & .000 & .999 & 10.0 & & $2.5 e+10$ \\
\hline cloud ice & ice & 40 & 20 & 1.7 & 1.31 & .000 & .999 & 0.5 & & $1.1 \mathrm{e}+08$ \\
\hline
\end{tabular}

* 5 extra sizes for SU: $\quad r e=.06 u m(0.03 u m / 1.7), .10(.05 / 1.7), .26(.13 / 1.7), .40(.20 / 1.7), .64(.32 / 1.7)$

* 4 larger sizes for DU: $r e=2.5 \mathrm{um}(1.2 \mathrm{um} / 1.70), 4.0(1.6,1.85), 6.5(2.0,2.00), 10.0(2.5,2.50)$
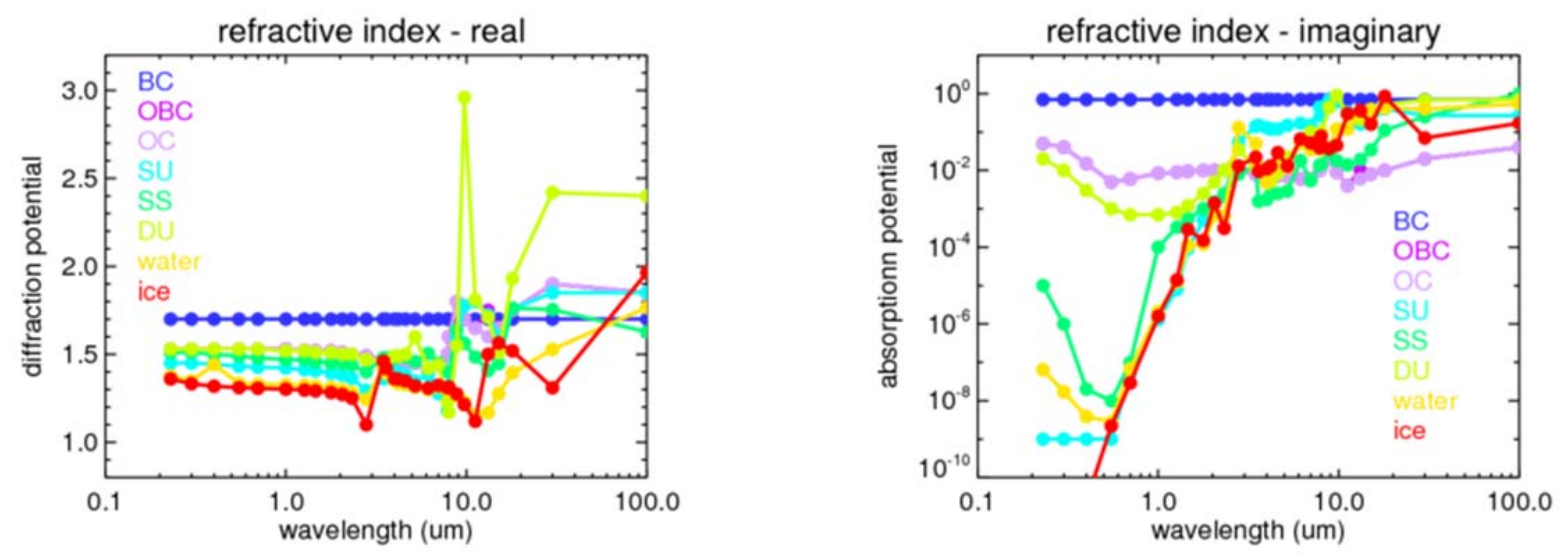

Figure 5 assumed real (left block) and imaginary part (right block) parts of the refractive indices for the different aerosol components (and for water and ice) of Figure 4 for central wavelengths representing the 30 spectral bands of the RRTM radiative transfer model

To account for the solar absorption enhancement as scattering material attaches on soot within a few hours, soot (BC) properties are prescribed by a CA type: a BC (soot) core with an OC shell. As sizes for SU (actually representing the non-absorbing fine-mode type) and DU are allowed to vary, several sizes for these components are pre-defined, ranging from 0.05 to 0.64 um in effective radius for SU and from 1.5 to 10 um for DU. More details on size choices for these two components is given below.

3.3 how are components assigned? To assign the predefined aerosol components to the MACv2 data (AODf, AODc, AAODf, AAODc), first the mid-visible AAOD for each component is determined via (MIE-) 
scattering simulations (Dave, 1968). With the size (-distribution) assumptions of Table 1 and Figure 4, SU, OC and CA only contribute to AODf, while DU and SS only contribute to AODc. Based on smaller than 0.99 component SSA data (which indicate absorption) in the mid-visible, as listed in Table 1, only CA and OC components contribute to AAODf and only the DU component contributes to AAODc. To start the component assignment, some ancillary data are applied. Local monthly carbon (BC+OC) AOD fractions from 'bottom up' modeling provide an initial guess for the likely fine-mode split between absorbing (CA) and non-absorbing (SU) fine-mode AOD. And maps of the near-surface wind-speed from re-analysis and an ocean influence weight factor map (1.0 over oceans but increasingly lower fractions with distances from the coast over continents) are used for first estimates of the coarse-mode sea-salt (SS) component.

3.3.1 coarse mode assignments: For the coarse mode component properties, ocean weight (ocean), wind-speed (wind), local latitude (lat) and the sun's seasonal varying latitude position (sun) define initial estimates for the coarse mode AOD of sea-salt (SS_AODc,ini):

$$
\text { SS_AODc,ini }=\text { ocean } * 0.03 * \text { wind } *(2.0-\cos (2.0 * \text { lat }-\operatorname{sun} / 2.0))
$$

The remaining coarse-mode AOD, after removing this seasalt AOD estimate, is attributed to dust. Now the (reasonable) assumption is made that the dust aerosol size increases with an increasing dust AOD. Hereby, an increasing dust size is expressed by an increasing absorption potential (1-SSA) starting from a value of 0.04 for the smallest considered mineral dust with an effective radius of $1.5 \mathrm{um}$. Next, the MACv2 coarse-mode absorption (AAODc) is applied to assign the dust AOD (DU_AODc). Remember that only dust contributes to the mid-visible coarse-mode absorption, while sea-salt does not.

\section{DU_AODc $=$ AAODc $/(0.04+0.08 *$ sqrt(1-SS_AODc,ini $)), \quad$ SS_AODc $=1-D U \_A A O D c$}

An additional constraint is used that this DU_AODc value has to stay between a maximum (AODc $0.6 * S S \_A O D c$,ini) and a minimum (AODc $-1.6 *$ SS_AODs, ini) value, with respect to the seasalt AOD estimate. In rare cases of exceedance, absorption is allowed to be transferred between the size-modes, to assure that the overall aerosol absorption is maintained. Now with coarse-mode AOD (AODc) set, the coarse mode absorption potential (AAODc/DU_AODc) defines the effective radius for dust (DU), which is allowed to vary between 1.5 to $10 \mathrm{um}$. Note, that only with a relatively low refractive index imaginary part of 0.001 for dust in the mid-visible region the AAODc data over the Sahara yield the expected mineral dust size increase near sources.

3.3.2 fine mode assignments: For the fine-mode component properties, two carbon types are pre-defined. These are represented by a (in the mid-visible spectral region) weakly absorbing organic carbon $(\mathrm{OC})$ type and a mixed carbon type (CA) with a strongly absorbing soot $(\mathrm{BC})$ core surrounded by a weakly absorbing OC shell. Both carbon types were assigned an effective radius of $0.12 \mathrm{um}$. Global modeling helps with an initial guess, how much of the fine-mode AODf of MACv2 is available for carbon. The fine-mode absorption AAODf of MACv2 then defines AODf contributions of CA and OC types. Note, that the $C A$ contributes twice as much to $O C$ than to $B C$. Then the ratio between the assigned OC AODf (from external and mixed contributions) and the BC AODf is tested. If the ratio remains below 5 , then the model suggested $\mathrm{OC} / \mathrm{BC}$ ratio carbon fraction is raised to 5 at the expense of the remaining (non- 
absorbing) fine-mode $A O D$, represented by the sulfate (SU) type. Finally, to reproduce the fine-mode effective radius (REf) of MACv2, the effective radius for $S U$ is allowed to vary between 0.06 to 0.64 um.

3.3.3 component AOD maps: The resulting annual average mid-visible AOD attributions to the pre-defined components of Table 1 and Figures 4 and 5 are presented in Figure 6 . The component AOD data for soot $(B C)$, organic carbon $(O C)$, total carbon $(B C+O C)$ and non-absorbing fine mode $(S U)$ are consistent with MACv2 properties for AODf and AAODf. And the component AOD attributions to mineral dust (DU) and seasalt (SS) consistent with MACv2 properties for AODc and AAODc .

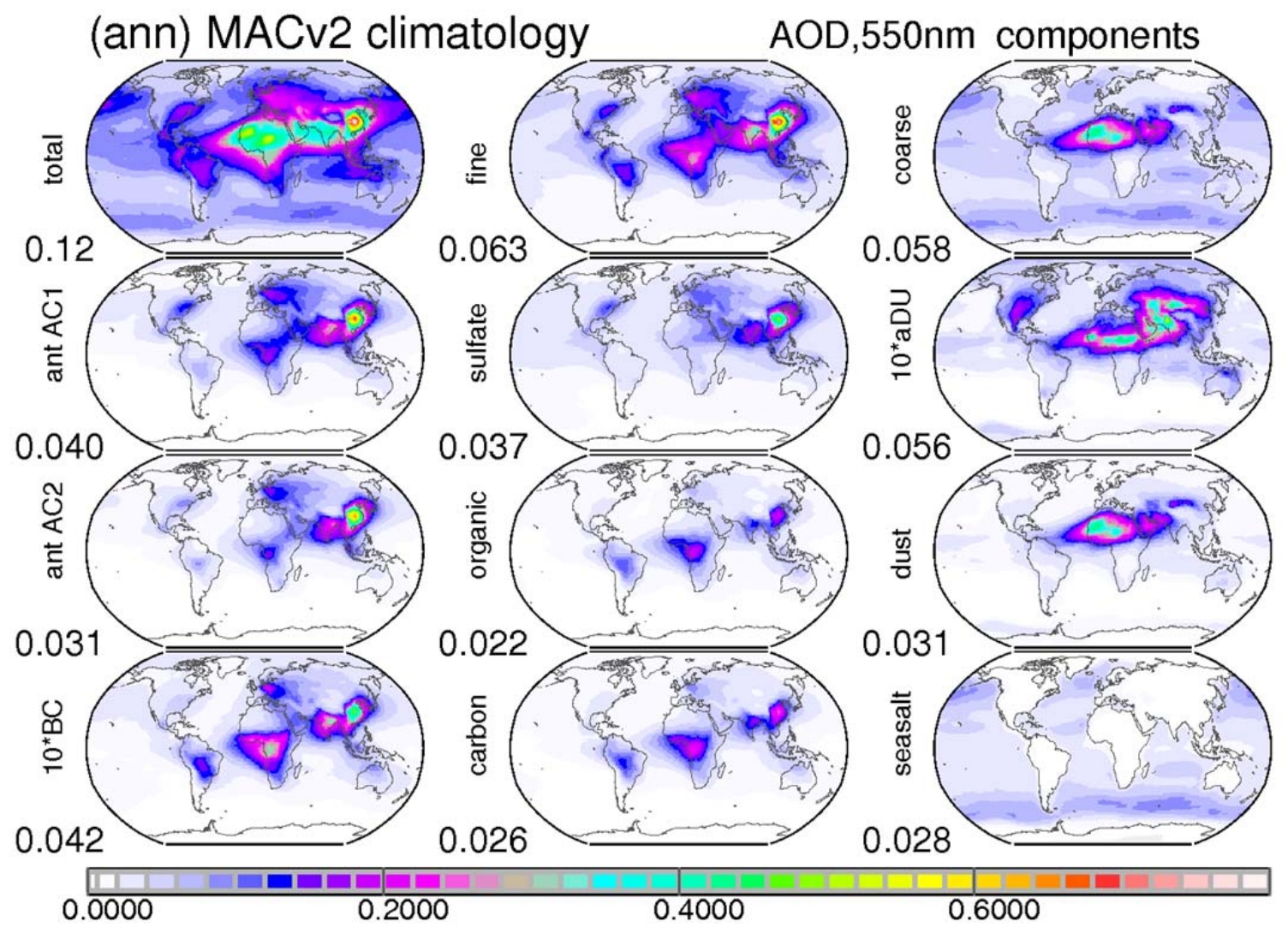

Figure 6 annual average AOD maps for today's tropospheric aerosol for total (top left) and contributions by fine-mode aerosol sizes (top center) and coarse-mode aerosol sizes (top right). In addition, consistent with mid-visible absorption data, component $A O D$ values were assigned. The fine-mode $A O D$ is divided into contributions by $B C$ (soot, here multiplied by 10), OC (organics) and SU (where SU represents nonabsorbing fine-mode). The coarse mode $A O D$ is split into contributions by sea-salt and dust. In addition, annual $A O D$ maps are presented for total carbon $(O C+B C)$, for today's anthropogenic dust ('aDU', here multiplied by 10 , based on fractions provided by $P$. Ginoux) and two different estimates of today's anthropogenic fine-mode $A O D$ : 'ant $A C 1$ ' is based on a fine-mode $A O D$ fraction of AeroCom1 simulation and used in the MACV1 climatology, 'ant AC2' is based on a fine-mode AOD fraction of AeroCom 2 and used in the MACV2 aerosol climatology). Values below the labels indicate global averages. 
3.3.4 SU and DU size: The size for the coarse-mode mineral dust component (DU) is defined by the strength of MACv2 AAODc for the DU_AODc assigned to dust (assuming a mid-visible refractive index imaginary part of 0.001). The size for the non-absorbing fine mode (SU) is defined by the assigned fine-mode AOD components and the MACv2 fine-mode radius (Ref) in the context of the carbon 0.12um effective radii. Monthly maps for the resulting effective radii for DU and SU are presented in Figure 7. Hereby, any particular size is approximated by a linear combination of the closest pre-defined sizes.
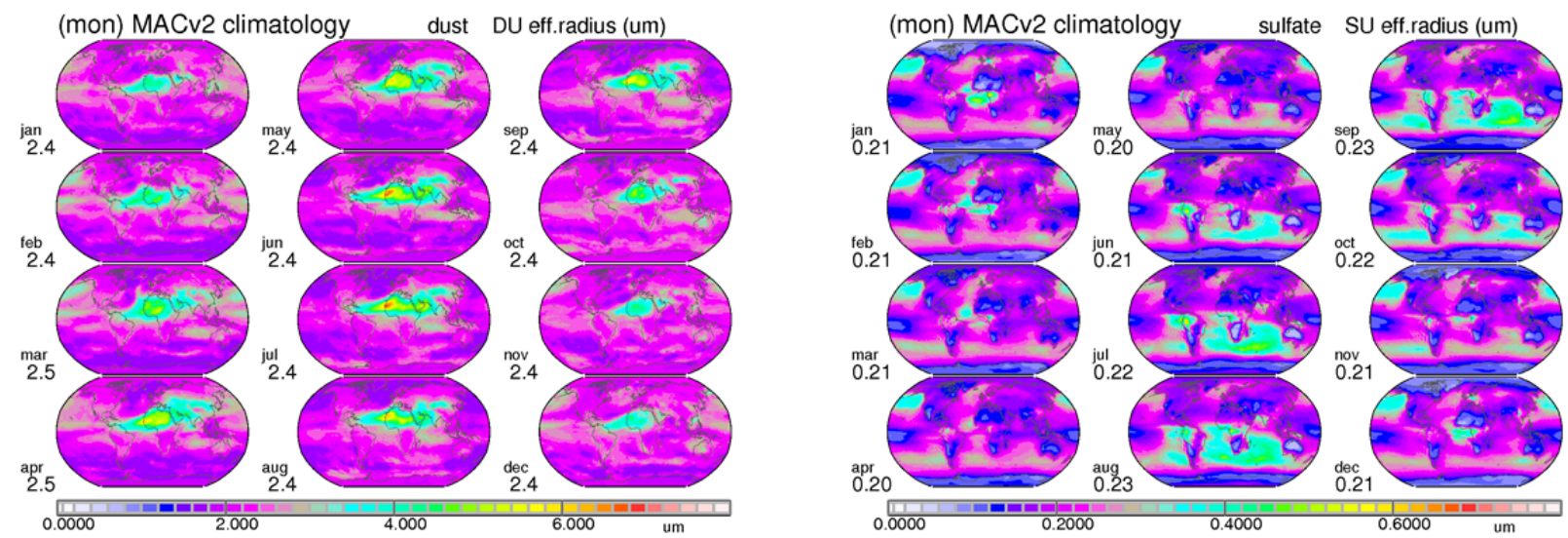

Figure 7 monthly effective radii (in um) for dust (left block) based on MACV2 AAODc data and effective radii (in um) for the non-absorbing fine-mode type (right block, SU), based on MACV2 REf data.

\section{4. anthropogenic}

4.1 what is anthropogenic? Anthropogenic contributions are essential for climate change assessments. Anthropogenic aerosol is defined by the extra aerosol since pre-industrial times as a result of human activities. While today's aerosol properties can be measured, the needed pre-industrial reference requires many assumptions. Usually, there is a reliance on 'bottom-up' simulations with global models, where different back-scaling assumptions (e.g. considering changing population and changing habits) are applied to define emission scenarios at those pre-industrial times. MAC assumes that the additional anthropogenic emissions only contributed to the fine-mode aerosol properties. Thus, simulated AODf maps based on simulations of many different global models with today's emissions and with preindustrial emissions were compared. The increase in AODf from pre-industrial times was captured by a fraction of today's fine-mode AOD. This definition has the advantage that anthropogenic contributions are not influenced by variability to natural aerosol (e.g. wind-speed impacts on dust and humidity impacts on seasalt). Two different choices for anthropogenic fractions are offered yielding quite different anthropogenic AOD maps when applied to the fine-mode AOD of MACv2. 
4.2 today's anthropogenic AOD with AeroCom1: The first choice for today's anthropogenic AOD is based on simulations with AeroCom 1 emissions (as they were prescribed in AeroCom phase1 experiments) for the years 2000 and 1750 (Dentener et. al, 2006). This choice when applied to the finemode AOD of MACv2 yields the 'ant AC1' - AOD distribution of Figure 7. The associated global annual average mid-visible AOD is 0.040 . This is ca $70 \%$ of today's fine-mode AODf and ca $33 \%$ of today's total AOD. This anthropogenic AOD was used in MACv1 (Kinne et al., 2013).

4.3 today's anthropogenic AOD with AeroCom2: The second choice for today's anthropogenic AOD is based on simulations with AeroCom 2 emissions (as they were prescribed in AeroCom phase 2 experiments and suggested for the IPCC5 intercomparison) for the years 2000 and 1850 (Lamarque et. al, 2010). This choice, when applied to the fine-mode AOD of MACv2 yields the 'ant AC2'- AOD distribution of Figure 7. The associated global annual average mid-visible AOD is 0.031 . This is ca $50 \%$ of today's fine-mode AODf and ca $25 \%$ of today's total AOD. This anthropogenic AOD was used in MACv2 and also served as basis in the plume approximation of MACv2-SP (Stevens et al., 2017).

4.4 anthropogenic AOD as function of time: As in MACv1 (Kinne et al., 2013), year-to-year variations are considered for the anthropogenic AOD, in order to simulate radiative impacts for anthropogenic aerosol change over time. For past anthropogenic AOD, the build-up of anthropogenic AOD since preindustrial times (here the year 1850) follows in a relative sense that of a transient 'bottom-up' ECHAM simulation with NIES emissions. Future anthropogenic AOD maps are defined by responses to regional changes in sulfate emissions based on the IPCC 5 RPM 8.5 future scenario. Global distributions for mid-visible anthropogenic AOD and total AOD (note, only anthropogenic AOD was allowed to change) are presented in 20 year time-slices from 1865 to 2085 in Figure 8. The maps show that significant shifts (away from Europe and the US to SE Asia) occurred for the anthropogenic AOD in recent decades and that the global average anthropogenic AOD today has reached its maximum with expectation of an overall decline over the next decades.
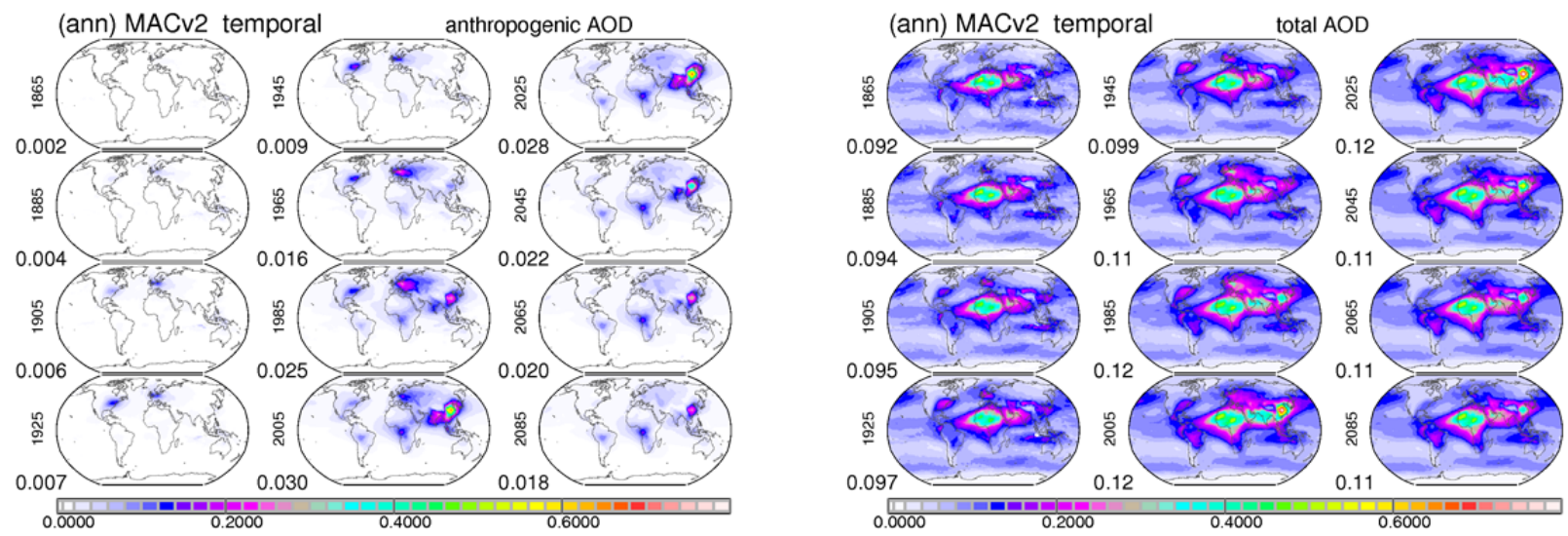

Figure 8 annual AOD (at 550nm) maps in 20 steps from 1865 to 2085 for anthropogenic (left block) and total aerosol (right block) in the troposphere. Values below the label indicate global averages. 
4.5. anthropogenic SSA and anthropogenic ASY: Composition and size, expressed via single scattering albedo (SSA) and asymmetry-factor (ASY) in MACV2 is assumed to be that of the fine-mode aerosol. This is certainly a simplification, especially in the context of temporal change, as between 1950 and 1980 with a stronger SU component - anthropogenic aerosol was less absorbing compared to anthropogenic composition of 100 years ago or today. Compared to AOD changes this simplification seems secondary.

\section{5. spectral spread}

5.1 why spectral spreading? Radiative transfer applications require aerosol properties not just at a midvisible wavelength. For instance, satellite remote sensing needs to apply aerosol properties at its sensor wavelengths and investigations of aerosol radiative effects (including climate impact investigations) require associated aerosol radiative properties at all solar and all infrared wavelengths of the applied radiative transfer code. The with aerosol size (-distribution) and aerosol composition associated radiative properties are the Aerosol Optical Depth (AOD, for aerosol amount), the Single Scattering Albedo (SSA, for the scattering potential) and the ASYmmetry-factor (ASY, to describe the scattering pattern). As a function of size (in comparison to the applied wavelength) and as a function of composition all three aerosol radiative properties (AOD, SSA and ASY) vary with wavelength.

5.2 components make it easy: Each pre-defined aerosol component is associated with spectrally varying refractive indices (e.g. as illustrated in Figure 5 for the central wavelengths of the RRTM radiative transfer scheme). For each pre-defined aerosol component of Table 1 its spectral radiative properties (AOD, SSA and ASY) are easily defined via (MIE-) scattering methods. For spectral overall properties, these component properties just need to be combined according to AOD contributions by each component (as illustrated for annual averages of today's aerosol in Figure 6). Hereby, the mixing rules need to be remembered. While the combination of AOD is additive, combinations of SSA data require AOD weights and combinations of ASY data require AOD*SSA weights. Global annual averages of AOD, SSA and ASY for total, coarse-mode, fine-mode and anthropogenic aerosol are summarized in Table 2 at a few selected wavelengths. Associated annual maps are presented in the Appendix.

Table 2 global annual average aerosol radiative properties of today's (tropospheric) aerosol

\begin{tabular}{|c|c|c|c|c|c|c|c|c|c|c|}
\hline & & AOD & & & & SSA & & & ASY & \\
\hline$\lambda(\mu \mathrm{m})$ & total & coarse & fine & anthr* & total & coarse & fine & total & coarse & fine \\
\hline .45 & .144 & .058 & .087 & .043 & .902 & .905 & .900 & .718 & .789 & .670 \\
\hline .55 & .122 & .058 & .063 & .032 & .941 & .964. & .919 & .702 & .767 & .639 \\
\hline 1.0 & .081 & .062 & .019 & .009 & .956 & .982 & .870 & .693 & .736 & .533 \\
\hline 10 & .049 & .049 & & & .580 & . 560 & & .605 & .605 & \\
\hline
\end{tabular}

* anthropogenic SSA and ASY are that of the fine-mode 


\section{6. vertical distribution}

6.1 how vertically distributed? All properties discussed so far refer to column averages. The aerosol vertical distribution, however, is important for the IR radiative transfer (e.g. greenhouse effects of elevated mineral dust) and for aerosol interactions with clouds (e.g. relative altitude to clouds matters). In MACv2 the aerosol vertical distribution (via a scaling approach, so that the column average property is maintained) addresses only the AOD. However, via a recommended separate treatment for fine-mode and coarse-mode aerosol properties in MACV2 applications, major impacts by vertical changes to SSA and ASY are then automatically included.

6.2 ECHAM modeling: The prescribed vertical distribution of the MACV2 AOD within the troposphere is based on 20-years (1986-2006) of 'bottom-up' simulations with the ECHAM-HAM global model for total aerosol and more importantly for coarse-mode and accumulation-mode only aerosol. In comparisons to active remote sensing from space, ECHAM-HAM simulations demonstrated one of the better skill scores for AOD vertical distributions among tested AeroCom models (B.Koffi et al., 2016). The global annual averages for AOD, AODf and AODc in a relative and an absolute sense are presented for four pre-defined tropospheric sub layers in Table 3. Associated annual maps are given in the Appendix

Table 3 vertical distribution for the mid-visible AOD in the troposphere in MACv2

\begin{tabular}{|c|c|c|c|c|c|c|}
\hline & \multicolumn{3}{|c|}{ fraction of column AOD } & \multicolumn{3}{c|}{ AOD per layer } \\
\hline alt (km asl) & total & coarse & fine & total & coarse & fine \\
\hline $\mathbf{6 - 1 2}$ & 0.059 & 0.039 & 0.076 & 0.004 & 0.001 & 0.003 \\
\hline $\mathbf{3 - 6}$ & 0.097 & 0.093 & 0.104 & 0.015 & 0.006 & 0.009 \\
\hline $\mathbf{1 - 3}$ & 0.457 & 0.432 & 0.468 & 0.059 & 0.026 & 0.033 \\
\hline $\mathbf{0 - 1}$ & 0.364 & 0.419 & 0.323 & 0.041 & 0.024 & 0.018 \\
\hline
\end{tabular}

\section{7. cloud nuclei}

7.1 aerosol as cloud particle nuclei? The cloud particle formation is usually helped, when aerosols are present and available. However, the affinity to serve as nuclei depends on aerosol composition, aerosol size and environment. Usually there is a distinction between nuclei for water clouds, referred to as Cloud Condensation Nuclei (CCN) and nuclei for ice clouds usually referred to as Ice Nuclei (IN). At lower altitude, where aerosol concentration are usually much higher, typical CCN concentrations range from about $30 / \mathrm{cm} 3$ in remote regions to more than $1000 / \mathrm{cm} 3$ in polluted regions. IN concentrations at a few/liter, in contrast, are much less frequent, with preferences for mineral dust and cold temperatures.

7.2 CCN concentrations: Usually all aerosols of the coarse-mode are large enough to serve as CCN, but only a fraction of the accumulation-mode aerosol qualifies. This fraction depends on the supersaturation (or upward wind at cloud-base altitude) and on the aerosol ability to attract water. The stronger the 
water attraction and/or the larger the supersaturations is, the smaller the aerosol sizes that can be activated. Four different supersaturations $(0.05,0.07,0.10$ and $0.20 \%)$ are assumed and the ability to attract water is expressed by the kappa parameter (Petters and Kreidenweiss, 2007). Hereby component kappa values of $\mathrm{BC}(0.0)$ of $\mathrm{OC}(0.1)$ and non-absorbing fine-mode $(\mathrm{SU}, 0.8)$ are combined according to their MACv2 fine-mode mixture by mass (by applying the listed mass extinction efficiencies of Table 1 , based on pre-defined density and size-distribution of a component). Then adding to the local kappa ( $k$ ) value information on local temperature $(T)$ and an applied supersaturation (SS) the critical dry radius cR_dry can be determined (Rose et.al, 2008, formula A32):

$$
\text { CR_dry (um) }=\left((4.0 *(.66 \mathrm{e}-6 / T) * * 3) /\left(27 * \mathrm{k}^{*} \ln (\mathrm{SS} / 100+1)\right) * * 2.0\right) * * .33
$$

Next, the dry radius $C R$ _dry needs to be converted into the wet radius $C R$ _wet in order to be applicable to ambient fine-mode size distributions. This is done by a simple parametrization that depends on kappa $\mathrm{k}$ and the ambient relative humidity $\mathrm{rh}$ (Petters and Kreidenweiss, 2007). As it is of interest to define the CCN concentrations near a low altitude cloud base is assumed that the relative humidity (rh) is at $90 \%$.

$$
\text { CR_wet (um) }=\text { CR_dry } *\left(1+k^{*} \text { rh/(1-rh) }\right) * * .33, \quad r h=0.9
$$

$c R \_$wet are applied to the log-normal size-distribution of the accumulation mode. This distribution is defined of the fine-mode AOD and the fine-mode effective radius of the MACv2 climatology and an assumed standard deviation of 1.7. All accumulation-mode particles larger than $c R$ _wet and all coarse mode particles are counted as CCN. CCN concentrations at cloud base (ca. $1 \mathrm{~km}$ above ground) are determined by scaling column CCN data with the ratio of the fine-mode AOD fraction in the layer near the cloud-base and the layer thickness. CCN concentrations for different SS are presented in Figure 9.

critical radius - function of SS

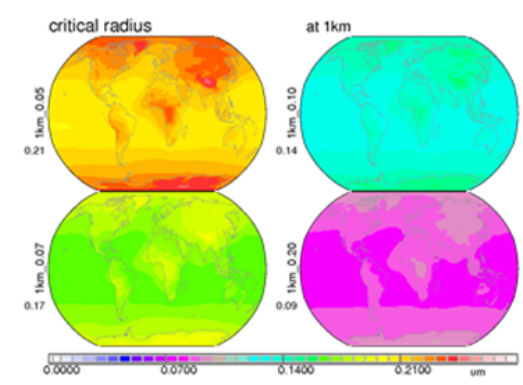

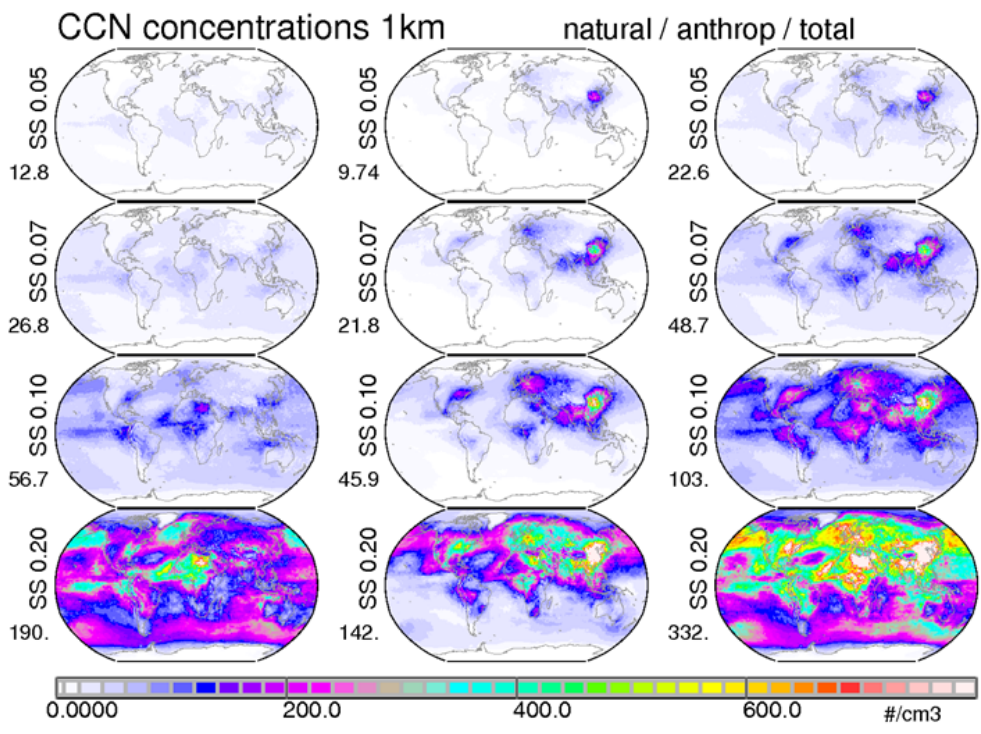

Figure 9 annual averages for critical radii (left block) at 4 different supersaturations: 0.05\% (upper left), $0.07 \%$ (lower left), $0.1 \%$ (upper right) and $0.2 \%$ (lower right). Corresponding CCN concentrations at lower cloud base as predicted by MACv2 for these for supersaturations presented as well (right block). Hereby natural, anthropogenic and total contributions are compared. 
A supersaturation of $0.1 \%$ yields the most realistic MACv2 based $C C N$ concentrations considering that at relative low CCN concentration almost all available CCN turn into Cloud Droplet Number Concentrations (CDNC). Also the comparison between natural and anthropogenic CCN concentrations is interesting as in regions of urban pollution anthropogenic concentration out number natural concentrations occasionally by even more than an order of magnitude. This anthropogenic increase in aerosol concentrations can be used to quantify anthropogenic aerosol indirect radiative effects - as increased aerosol concentrations tend to increase cloud drops concentrations in (low altitude) water clouds.

7.3 IN concentrations: It is assumed that only (coarse-mode) dust particles serve as IN and that this capability is sharply decreased when ambient temperatures get warmer than $238 \mathrm{~K}$ and even more so if warmer than $258 \mathrm{~K}$. The T-reduced IN efficiency for dust concentrations is expressed by the T-factor.

$$
\text { T_factor }=\exp (-\mathrm{A}) * \exp (-\mathrm{B}) \quad \mathrm{A}=0[\mathrm{~T}<238 \mathrm{~K}],=0.5 * \mathrm{~T}-238,=10[\mathrm{~T}>258 \mathrm{~K}], \quad B=0[\mathrm{~T}<258 \mathrm{~K}],=\mathrm{T}-258
$$

At selected three selected altitudes $(7,9$ and $12 \mathrm{~km})$ the dust component fractional AOD in that altitude layer (as defined by the coarse-mode vertical distribution) is divided by the layer thickness and then multiplied with the T-factor. The resulting 'IN' concentrations are presented in Figure 10, where dust IN are missing over the tropics at $7 \mathrm{~km}$ altitude due to too warm temperatures and is also missing over high latitudes at $12 \mathrm{~km}$ altitude, at that altitude there is already well in the stratosphere.
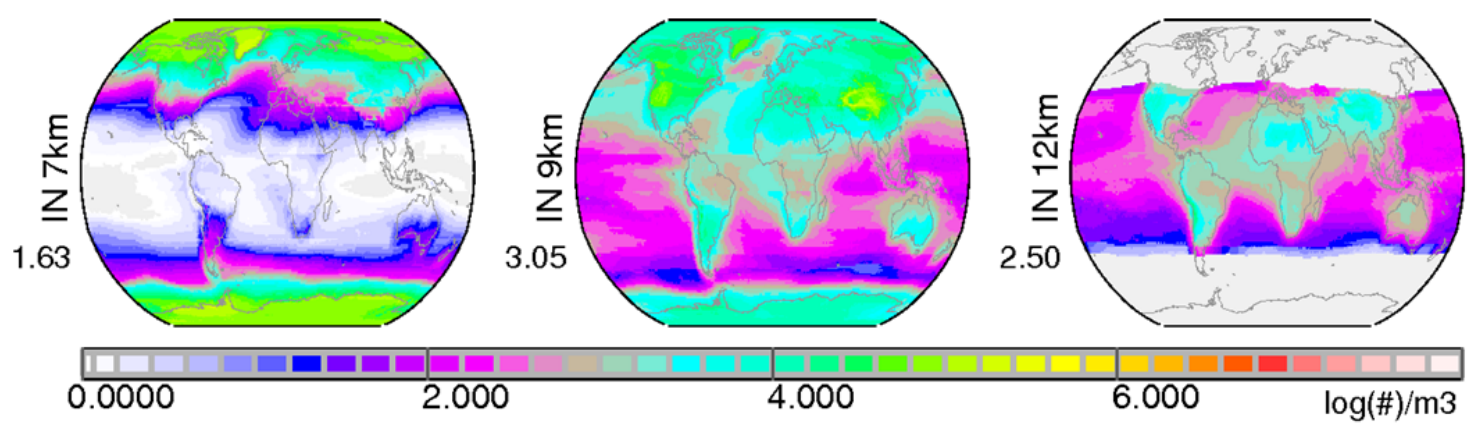

Figure 10 annual average estimates for IN (dust) concentrations at $7 \mathrm{~km}$ (left), at $9 \mathrm{~km}$ (center) and at $12 \mathrm{~km}$ (right). Note the log10 axis, so that 2 refers to $100(/ \mathrm{m3})$ and 6 to $1000000(/ \mathrm{m}-3)$.

\section{8. retrieval assistance}

8.1 how to help satellite retrievals for aerosol ? The local and monthly variability captured by the aerosol properties of the MACV2 climatology can help under-determined satellite retrievals for AOD with smart assumptions to aerosol size and absorption, although other uncertainties (e.g. the solar surface reflectance) remain open issues.

8.2 how to simplify size? A bi-modal size-distribution is assumed, as in most aerosol retrievals models. Such a size-distribution shape is almost always retrieved with ground based sun-/sky photometry 
(Dubovik et al., 2002) separating with a minimum concentration near radii of 0.5 um between a finer and a coarser size mode. Based on most frequent occurrences of all AERONET size-distribution samples, as illustrated in Figure 11, a most frequent effective radius of $0.145 \mathrm{um}$ is picked to represent the fine-mode and a most frequent effective radius of $1.9 \mathrm{um}$ is chosen to represent the coarse mode. Hereby each mode is described by log-normal shaped size distributions defined by mode-radius and standard deviation. The mode radius ( $r$, mode: fine $=0.096 u m$, coarse $=0.97 u m$ ) defines the size with the largest number concentration and the standard deviation (std.dev.: fine $=1.5$, coarse $=1.7$ ) defines the distribution width.

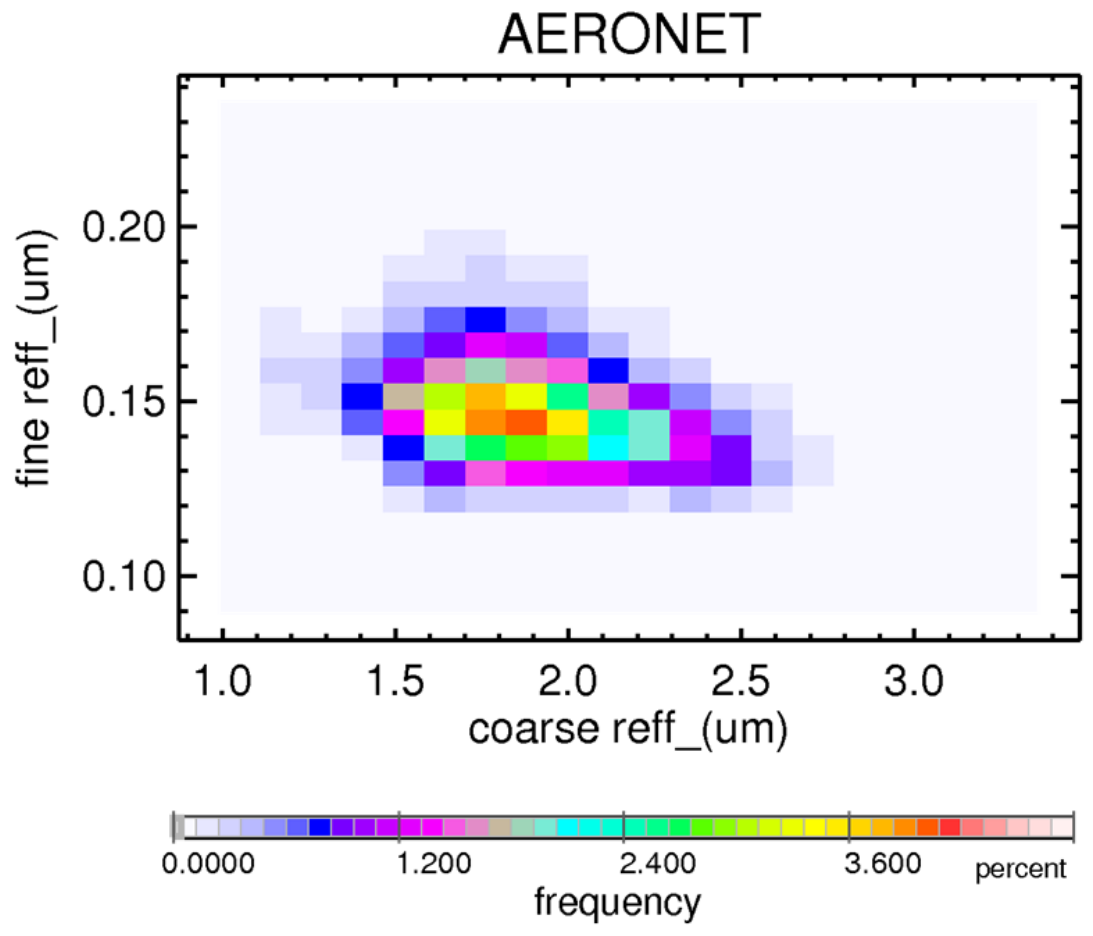

Figure 11 frequency of coarse-mode effective radius ( $x$-axis) and fine-mode effective radius ( $y$-axis) based on size-distribution detail of AERONET at all available sites (11245 monthly averages in total)

8.3 how to simplify absorption? For both assumed log-normal distributions (to represent the fine-mode and the coarse mode) a non-absorbing ( $S S A=1.0)$ composition and a strongly absorbing composition are defined. Hereby the strongly absorbing type was chosen to be so strong (for .550nm: fine SSA $=.7693$, coarse SSA $=.7457$ ) that any absorption can be determined by interpolation. Then for these (in total) four size-distributions (sensor-specific) look-up tables are prepared. In an application based on MACv2 suggested absorption data for each mode (see annual averages for AAODf and AAODc in Figure 3) an absorbing type fraction and its remaining scattering fraction, as illustrated in Figure 12, are defined so that the required AAODf and AAODc data are matched. 
8.4 steps of application: First MACv2 suggested AODf/AOD and AODc/AOD ratios each apply the nonabsorption and the strongly absorbing types in fractions so that MACV2 suggested AAODf and AAODC are matched. Then, based on the look-up tables a total AOD is retrieved and compared to the suggested total AOD of MACv2. In case of a difference, via the difference factor the MACv2 prescribed fine-mode AOD fraction (AODf/AOD) is adjusted - based on multi-annual statistical relationships from ICAP satellite data assimilation ensemble data between AOD and AODf/AOD (Peng et al., 2018). Figure 12 indicates that as the AOD increases on average the AODf/AOD decreases but this may vary locally. Finally with the adjusted $A O D f / A O D$ and $A O D c / A O D$ ratios the $A O D$ retrieval is repeated for the final $A O D$ estimate.
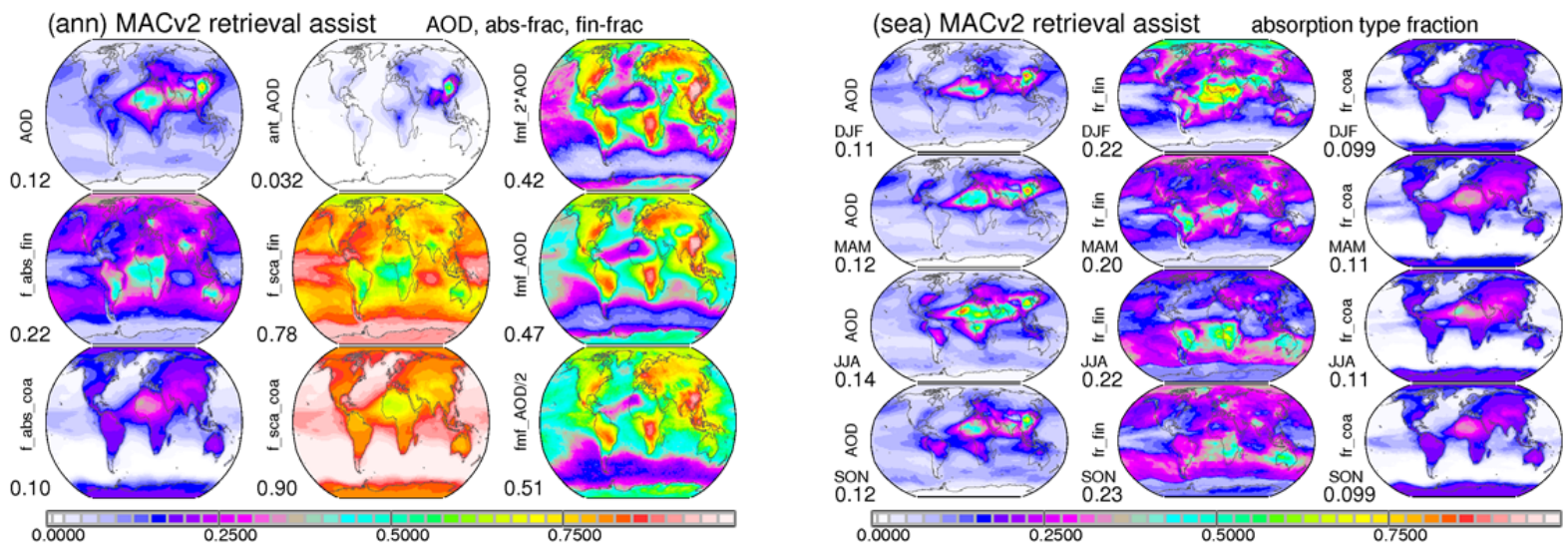

Figure 12 MACv2 associated mid-visible global maps for assistance in aerosol model choices in satellite retrievals. Annual averages (left block, left column) and seasonal averages (right block) are presented for total $A O D$ at 550nm and absorption type fractions for fine-mode AOD and coarse mode AOD. The $A O D$ split is assigned by the fine mode fraction whose annual averages (left block, right column) are presented for twice the MACV2 AOD, for the standard MACV2 AOD and half the MACV2 AOD. In the context of the absorption fraction, absorption types have a single scattering albedo of .7693 (SSAf) and .7457 (SSAC) for fine-mode and coarse-mode, respectively, while the alternate scattering types have a single scattering albedo of 1.0. Note, the coarse mode absorption includes enhanced absorption by larger mineral dust sizes. Also shown in the left block are annual averages for (today's) anthropogenic $A O D$ and the complementary scattering fractions. 


\section{Resources}

MACv2 properties are accessible at ftp://ftp-projects.zmaw.de/aerocom/climatology/MACv2 2018/. The data are placed in several subdirectories and a README file describes data content of file-names

- /550nm (mid-visible) aerosol properties at 550nm wavelength

- /CCN lower cloud-base condensation nuclei and critical radii at diff. supersaturation

- /detail ancillary data for radiative transfer simulations

- /documents some documentation and figures

- /forcing MACv2 associated radiative effects

- /retrieval MACV2 fields for under-determined solar reflection based AOD retrievals

- Ispectral 2005 optical data at 3 different spectral resolutions: 20, 30 (RRTM),31 bands

- /time $\quad$ same as in /spectral ... but data for different years (from 1850 to 2100)

\section{Acknowledgments}

This study relied on observational data when possible. Central to the effort are data provided by the ground-based sunphotometer network of AERONET lead by B. Holben and the MAN network lead by A. Smirnov. Another essential element to this study is global model output from simulations with bottomup processing in aerosol modules as part of the AeroCom initiative lead by M. Schulz and M. Chin. An ensemble median provides data on spatial context, estimates on aerosol anthropogenic fractions (also as a function of time) and aerosol vertical distribution. Thus, all modeling groups contributing to AeroCom experiments are acknowledged. Finally, this work was support by EU-projects, in particular the FP7 EU-Bacchus project (603445) lead by U.Lohmann and by ESA's climate initiative, in particular the aerosol-CCl effort lead by T. Popp and G. de Leeuw and coordinated by S. Pinnock.

\section{References}

\section{Dave, J.V. (1968): Subroutines for Computing the Parameters of the Electromagnetic Radiation Scattered by Spheres Report No. 320-3237, May 1968.}

Dentener, F., S. Kinne, T. Bond, O. Boucher, J. Cofala, S. Generoso, P. Ginoux, S. Gong, J.J. Hoelzemann, A. Ito, L. Marelli, J.E. Penner, J.-P. Putaud, C. Textor, M. Schulz, G.R. van der Werf and J. Wilson (2006): Emissions of primary aerosol and precursor gases in the years 2000 and 1750, prescribed datasets for AeroCom, ACP, 6, 4321-4344.

Dubovik, O., A. Smirnov, B. N. Holben, M. D. King, Y.J. Kaufman, T. F. Eck, and I. Slutsker (2000): Accuracy assessments of aerosol optical properties retrieved from AERONET sun and sky-radiance measurements, J. Geophys. Res., 105, 9791-9806. 
Dubovik, O., B. Holben, T.Eck, A. Smirnov, Y. Kaufman, M. King, D. Tanre, I. Slutsker (2002): Variability of Absorption and Optical Properties of Key Aerosol Types Observed in Worldwide Locations, J.Atmos.Sci, Vol 38, 580-608.

Holben, B.N., D. Tanre, A. Smirnov, T.F. Eck, I. Slutsker, N. Abuhassan, W.W. Newcomb, J. Schafer, B. Chatenet, F. Lavenue, Y.J. Kaufman, J. Vande Castle, A. Setzer, B. Markham, D. Clark, R. Frouin, R. Halthore, A. Karnieli, N.T. O'Neill, C. Pietras, R.T. Pinker, K. Voss, and G. Zibordi (2001): An emerging ground-based aerosol climatology: Aerosol Optical Depth from AERONET, J. Geophys. Res., 106, 12067-12097.

Kinne, S., D. O'Donnel, P. Stier, S. Kloster, K. Zhang, H. Schmidt, S. Rast, M. Giorgetta, T. F. Eck, and B. Stevens (2013): MAC-v1: A new global aerosol climatology for climate studies, J. Adv. Model. Earth Syst., 5, 704-740, doi:10.1002/james. 20035.

Kinne S., M. Schulz, C. Textor, S. Guibert, S. Bauer, T. Berntsen, T. Berglen, O. Boucher, M. Chin, W. Collins, F. Dentener, T. Diehl, R. Easter, J. Feichter, D. Fillmore, S. Ghan, P. Ginoux, S. Gong, A. Grini, J. Hendricks, M. Herzog, L. Horowitz, I. Isaksen, T. Iversen, D. Koch, M. Krol, A. Lauer, J.F. Lamarque, G. Lesins, X. Liu, U. Lohmann, V. Montanaro, G. Myhre, J. Penner, G. Pitari, S. Reddy, O. Seland, P. Stier, T. Takemura and X. Tie (2006): An AeroCom initial assessment-optical properties in aerosol component modules of global models, ACP, 6, 1-22, 2006

Koffi, B.,M. Schulz. F.-M. Bréon, F. Dentener, B. M. Steensen, J. Griesfeller, D. Winker, Y. Balkanski, S. E. Bauer, N. Bellouin, T. Berntsen, H. Bian, M. Chin, T. Diehl, R. Easter, S. Ghan, D. A. Hauglustaine, T. Iversen, A. Kirkevåg, X. Liu, U. Lohmann, G. Myhre, P. Rasch, Ø. Seland, R. B. Skeie, S. D. Steenrod, P. Stier, J. Tackett, T. Takemura, K. Tsigaridis, M. R. Vuolo, J. Yoon and K. Zhang, (2016): Evaluation of the aerosol vertical distribution in global aerosol models through comparison against CALIOP measurements: AeroCom phase II results, J.Geophys.Res, 121, 7254-7283.

Köpke, P, M. Heß, I. Schuldt and E. Shettle (1997): Global Aerosol DataSet, Report 243, Max-Planck Institut für Meteorologie.

Lamarque, J.-F., Bond, T. C., Eyring, V., Granier, C., Heil, A., Klimont, Z., Lee, D., Liousse, C., Mieville, A., Owen, B., Schultz, M. G., Shindell, D., Smith, S. J., Stehfest, E., Van Aardenne, J., Cooper, O. R., Kainuma, M., Mahowald, N., McConnell, J. R., Naik, V., Riahi, K., and van Vuuren, D. P. (2010): Historical (1850-2000) gridded anthropogenic and biomass burning emissions of reactive gases and aerosols: methodology and application, Atmos. Chem. Phys., 10, 7017-7039, doi:10.5194/acp10-7017-2010.

O'Neill, N., T.F. Eck, A. Smirnov, B. N.Holben and S. Thulasiraman (2003): Spectral discrimination of coarse and fine mode optical depth, J. Geophys. Res., 108, 4559-4573, 10.1029/2002JD002975.

Peng,Y. et al., (2018): Current state of the global operational aerosol multi-model ensemble: an update from the International Cooperative for Aerosol Prediction (ICAP) QJRMS submitted

Petters, M. D. and S. Kreidenweis (2007): A single parameter representation of hygroscopic growth and cloud condensation nucleus activity, Atmos. Chem. Phys., 7, 1961-1971. 
Rose, D., S. Gunthe, E. Mikhailov, G. Frank, U. Dusek, M.O. Andreae, and U. Pöschl (2008): Calibration and measurement uncertainties of a continuous-flow cloud condensation nuclei counter (DMTCCNC): CCN activation of ammonium sulfate and sodium chloride aerosol particles in theory and experiment, Atmos. Chem. Phys., 8, 1153-1179 (2008).

Stevens, B., S. Fiedler, S. Kinne, K. Peters, S. Rast, J. Müsse, S. Smith, S. \& T. Mauritsen (2017) : MACv2SP: a parameterization of anthropogenic aerosol optical properties and an associated Twomey effect for use in CMIP6. Geoscientific Model Development, 10, 433-452.

Smirnov, A., B. Holben, I. Slutsker, D. Giles, C. R. McClain, T. Eck, S. Sakerin, A. Macke, P. Croot, G. Zibordi, P. Quinn, J. Sciare, S. Kinne, M. Harvey, T. Smyth, S. Piketh, T. Zielinski, A. Proshutinsky, J. Goes, N. Nelson, P. Larouche, V. Radionov, P. Goloub, K. Krishna Moorthy, R. Matarrese, E. Robertson and F. Jourdin (2009): Maritime Aerosol Network as a component of Aerosol Robotic Network, J. Geophys. Res., 114, D06204, doi:10.1029/2008JD011257. 


\section{Appendix A}

In the Appendix A global maps for today'a annual average radiative properties (AOD, SSA, ASY) are listed for total, coarse-mode, fine-mode and anthropogenic aerosol at selected wavelengths
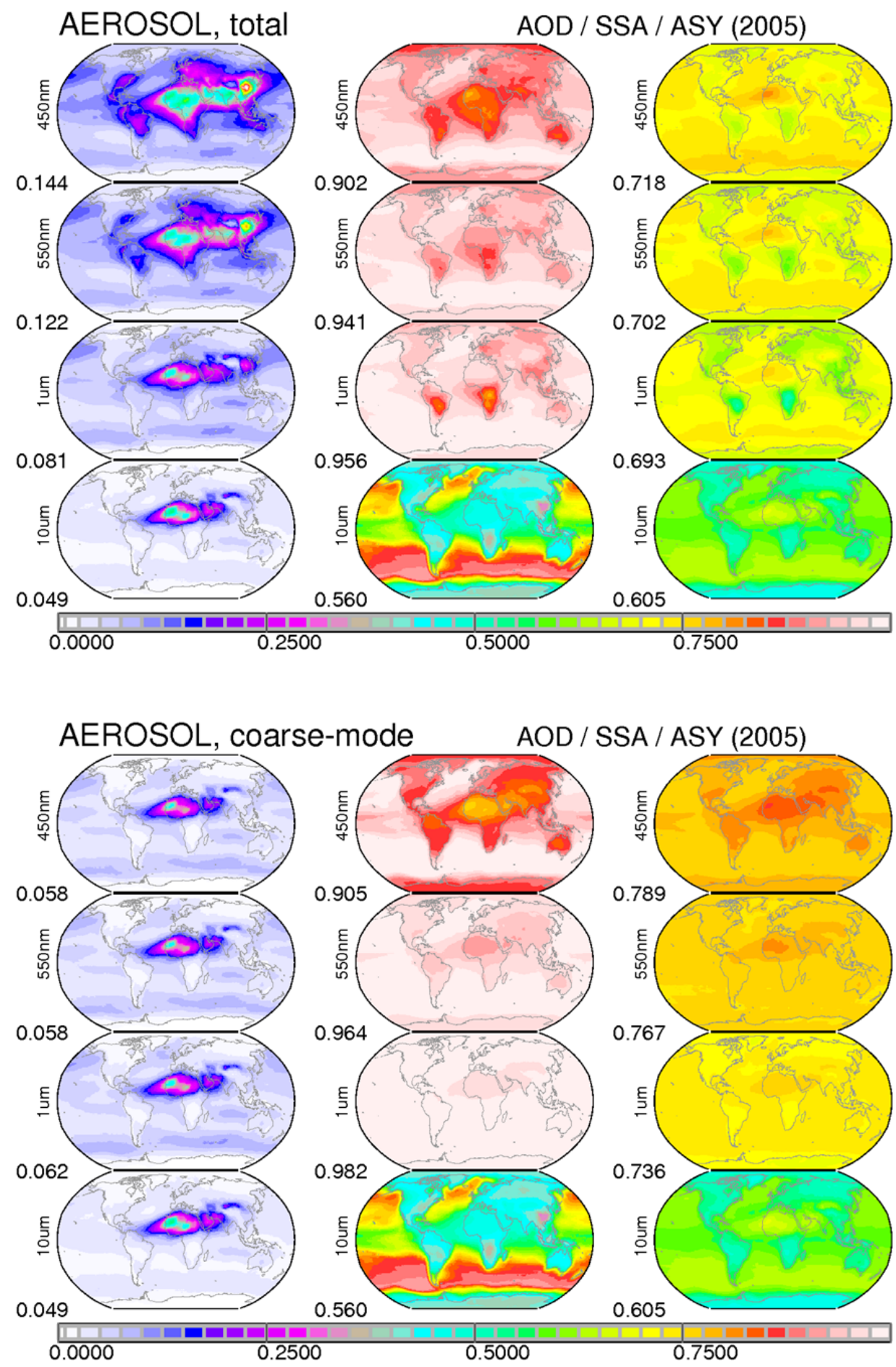

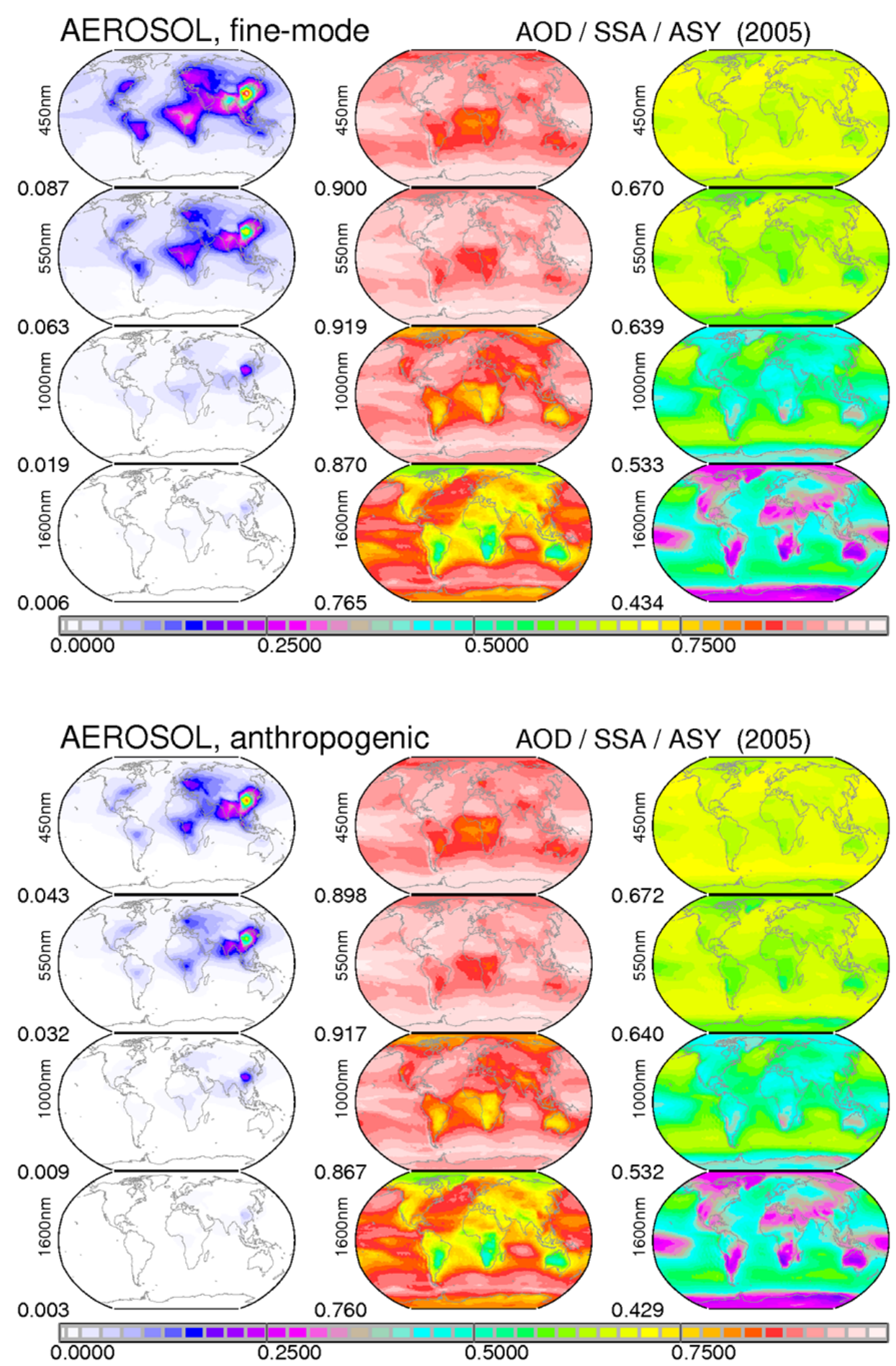

Note, that for anthropogenic aerosol the AOD is a fraction of the fine-mode AOD and the local values for anthropogenic SSA (or composition) and the anthropogenic ASY (or aerosol size) are assumed to be that of fine-mode aerosol. Also, in all plots the values below the labels indicate global average 


\section{Appendix B}

In the Appendix B global maps are presented for aerosol altitude distributions of AOD, AODf and AODc based on ECHAM HAM simulations with respect 4 atmospheric layers (asl): $0-1 \mathrm{~km}$ (row 4), 1-3km (row 3), $3-6 \mathrm{~km}$ (row 2) and 6-12km (row 1) above sea-level. Values below the labels indicate global averages.
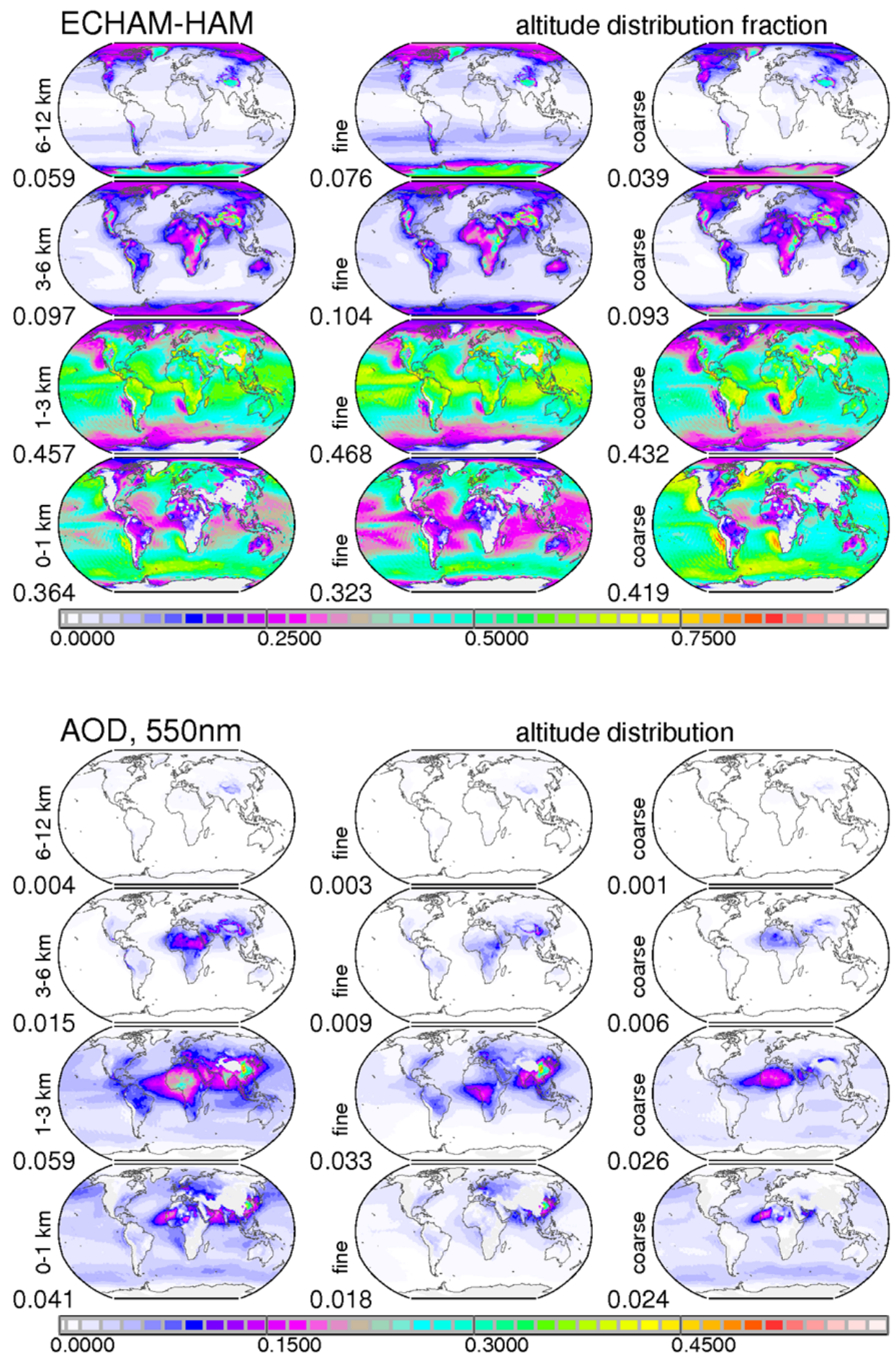